Artículo científico

Volumen 31(2):385-403. Mayo-agosto, 2020

e-ISSN 2215-3608, doi:10.15517/am.v31i2.38615

http://www.revistas.ucr.ac.cr/index.php/agromeso

\title{
Comparación de la productividad agrícola-económica sustentable y convencional de papaya, en Michoacán, México ${ }^{1}$
}

\section{Comparison of agricultural and economic productivity of sustainable and conventional papaya in Michoacan, Mexico}

\author{
José Mario Miranda-Ramírez $z^{2}$,Omar Aguilar-García ${ }^{3}$, Diana Miranda-Medina
}

1 Recepción: 13 de agosto, 2019. Aceptación: 9 de diciembre, 2019. Este trabajo se realizó como parte del proyecto de titulación del doctorado en ingeniería de la innovación para obtención del grado académico en el Instituto de Innovación y Desarrollo Tecnológico e Instituto Tecnológico Superior de Apatzingán.

2 Instituto Tecnológico Superior de Apatzingán, km. 3.5 carretera Apatzingán-Aguililla, CP 60710. Apatzingán, Michoacán, México. jose@ itsa.edu.mx (autor para correspondencia; https://orcid.org/0000-0003-3674-4629).

3 Instituto de Innovación y Desarrollo Tecnológico, Periférico paseo de la República 3279, colonia: Poblado Ocolusen, CP 58270, Morelia Michoacán, México.omarag@mail.com (https://orcid.org/0000-0002-1830-9968).

4 Instituto Tecnológico Superior de Apatzingán, km. 3.5 carretera Apatzingán-Aguililla, CP 60710. Apatzingán, Michoacán, México. diana. miranda.medina.24@gmail.com (https://orcid.org/0000-0001-7713-8081).

\section{Resumen}

Introducción. En Buenavista, Michoacán, México, la superficie sembrada de papaya (Carica papaya L.) es de la variedad Maradol Roja y la mayoría de los agricultores utilizan un modelo de producción agrícola convencional, donde no se conoce con certeza la productividad ni la rentabilidad del cultivo; conocer estas dos variables permitiría obtener una producción eficiente que a mediano plazo mejoraría el entorno socioeconómico de los agricultores. Objetivo. Comparar un modelo de producción agrícola sustentable contra el modelo de producción convencional de papaya, para identificar la producción agrícola y la relación beneficio-costo. Materiales y métodos. El experimento se llevó a cabo en el municipio de Buenavista, Michoacán, México, durante 2015. Se caracterizó por tener dos unidades experimentales, un tratamiento por unidad (sustentable y convencional) con un muestreo aleatorizado simple. Se evaluaron el peso de fruto, los sólidos solubles totales y los frutos por planta. El análisis estadístico incluyó prueba de Levene, prueba de Kolmogorov-Smirnov y Lilliefors, ANOVA y prueba no paramétrica U de Mann-Whitney. Se realizó análisis económico con los indicadores: costo total de la inversión, ingreso total, relación beneficio costo, rentabilidad y punto de equilibrio. Resultados. El modelo sustentable mostró para peso de fruto 1,71 kg, 38,0 frutos por planta, costo total de inversión de USD $\$ 8736,83 \mathrm{ha}^{-1}$, relación beneficio costo de 2,24, y un punto de equilibrio de $38,47 \%$. El modelo convencional mostró $2,20 \mathrm{~kg}$ en peso de fruto, 53,72 frutos por planta, un costo total de inversión

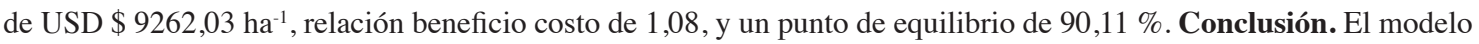
convencional resultó desfavorable económicamente, por lo que se sugiere mejorarlo gradualmente hasta llegar a ser rentable. El modelo sustentable mostró ser muy atractivo económicamente y tener aprovechamiento eficiente de los recursos naturales locales.

Palabras clave: Carica papaya L., manejo del cultivo, rendimiento de cultivo, inversión agrícola responsable, rentabilidad. 


\begin{abstract}
Introduction. In Buenavista, Michoacan, Mexico, the area planted with papaya (Carica papaya L.) is of the Maradol Roja variety and most farmers use a conventional agricultural production model, where the productivity and profitability of the crop is not known with certainty. culture; therefore, it is important to know these two variables in order to obtain an efficient production that in the medium term allows them to improve the socio-economic environment of the farmers. Objective. Compare a sustainable agricultural production model against the conventional papaya production model, to identify agricultural production and the cost-benefit ratio. Materials and methods. The experiment was carried out in the municipality of Buenavista, Michoacan, Mexico during 2015. It was characterized by having two experimental units, one treatment per unit [sustainable and conventional] with a simple randomized sampling. Fruit weight, total soluble solids, and fruits per plant were evaluated. Statistical analysis included Levene's test, Kolmogorov-Smirnov, and Lilliefors test, ANOVA and non-parametric Mann-Whitney U test. Economic analysis was carried out with the indicators: total investment cost, total income, cost-benefit ratio, profitability, and break-even point. Results. The sustainable model showed for fruit weight $1.71 \mathrm{~kg}, 38.06$, fruits per plant, total investment cost of USD $\$ 8,736.83 \mathrm{ha}^{-1}$, cost-benefit ratio of 2.24 , and an equilibrium point of $38.47 \%$. The conventional model showed $2.20 \mathrm{~kg}$ in fruit weight, 53.72 fruits per plant, a total investment cost of USD $\$ 9,262.03 \mathrm{ha}^{-1}$, cost-benefit ratio 1.08 , and an equilibrium point of $90.11 \%$. Conclusion. The conventional model was economically unfavorable, so it is suggested to gradually improve it until it becomes profitable. The sustainable model proved to be very economically attractive and to have efficient use of local natural resources.
\end{abstract}

Keywords: Carica papaya L., crop management, crop yield, responsible investment in agriculture, profitability.

\title{
Introducción
}

La papaya (Carica papaya L.) se produce en setenta países, principalmente en India, Brasil, México, Indonesia, República Dominicana y Nigeria (FAOSTAT, 2018). En México la papaya se cultiva en 18 771,99 ha anuales, con una producción de 961 768,25 t, valoradas en 261,4 millones de dólares (mdd). En Michoacán, México, se producen $79888,81 \mathrm{t}$ anuales de las cuales 27 820,3 t provienen del municipio de Buenavista y representan ingresos de 6,4 mdd (SADER-SIAP, 2019). La superficie mayormente sembrada corresponde a la variedad Maradol Roja, que es apreciada en el mercado mexicano y estadounidense (Posada et al., 2010; Mirafuentes y Santamaría, 2014).

El cultivo es atractivo para el agricultor, por su rentabilidad, periodo corto entre siembra y cosecha, y su rendimiento por hectárea (Arango y Roman, 2000; Mirafuentes y Azpeitia, 2008). En un estudio sobre rendimiento y calidad del cultivo de papaya en Mayabeque, Cuba, bajo un modelo de producción agrícola convencional (en cielo abierto), se obtuvo un rendimiento de $168,1 \mathrm{t} \mathrm{ha}^{-1}$ (Rivas et al., 2003). En otra investigación realizada en Tabasco, México, se observó un rendimiento de $84 \mathrm{t} \mathrm{ha}^{-1}$, con una rentabilidad indicada en relación beneficio costo de 2,73 (Guzmán-Ramón et al., 2008); mientras que en Yucatán, se obtuvo un rendimiento de 175,9 t ha-1 (Martin et al., 2012). Es importante señalar que la relación beneficio costo contribuye a determinar la viabilidad de la inversión, con ella se puede identificar si el beneficio obtenido es mayor al costo o viceversa.

El esquema de la producción agrícola convencional se sustenta principalmente en una nutrición a partir de la fertilización química intensiva que se adapta al cultivo por ser de crecimiento continuo, de respuesta rápida y acelerada (Escamilla et al., 2003), con una producción constante, susceptible a plagas y enfermedades y que también necesita de varios insumos (fungicidas, bactericidas, insecticidas, acaricidas y ovicidas) para obtener altos rendimientos. Sin 
embargo, la restricción de la utilización de estos insumos tiene como consecuencia bajos rendimientos en los cultivos (Storck et al., 2017; Vargas-González et al., 2019). Además, se caracteriza por practicar una labranza intensiva y los agricultores no prestan atención a la fertilidad del suelo a largo plazo, ignoran los procesos que lo mantienen (Gliessman, 1998) y utilizan herbicidas para el control de arvenses (Gliessman, 1998; Pengue, 2001). Este sistema de producción se basa en el monocultivo, y eso potencia las plagas, se suele usar productos que tienen su origen en el nitrógeno; pero es importante porque pueden integrarse las herramientas que van surgiendo de las innovaciones tecnológicas, con ello evolucionar y hacerlas extensivas, así como lograr mejoras en la producción; es un sistema productivo de carácter artificial (Franquesa, 2016), que en cierta manera intenta controlar los factores de producción para aumentar las cosechas. En síntesis, va creando una degradación del suelo física como la erosión hídrica y eólica, química que provoca pérdida de nutrientes o fertilidad, acidificación o alcalinización, y biológica con la pérdida de materia orgánica y alteración de la flora y fauna del suelo (Michelena, 2011).

Por otro lado, la sustentabilidad es un concepto complejo y multidimensional lo que dificulta su implementación (Flores y Sarandón, 2002). La producción agrícola sustentable se fundamenta en la producción a largo plazo que incide en el mejoramiento de la calidad del entorno, los recursos asociados, la cantidad y la viabilidad económica de la labor agrícola, redundando en la mejora de la calidad de vida del agricultor. Hace énfasis en el manejo integrado de plagas, insecticidas vegetales, abonos verdes, conservación del suelo, agua, energía y recursos biológicos, y utiliza prácticas locales (Serrato et al., 2017). Su sistema de abono se basa en la protección de la fertilidad de los terrenos, y utiliza en su mayoría abonos naturales (Franquesa, 2016); estos abonos naturales se apoyan en una nutrición vegetal adecuada, a partir de la sustitución total o parcial de fertilizantes químicos por biofertilizantes (Armenta et al., 2010) como alternativa económica para incrementar el rendimiento, utilizando el uso combinado de insumos inorgánicos, orgánicos y biológicos (López et al., 2010). No obstante, los resultados obtenidos mediante el empleo de biofertilizantes en la producción agrícola son muy variables, pero en términos generales es posible lograr aumentos en los rendimientos de los cultivos que varían del 15 al 50 \% (Moreno y Aguado, 2012).

Los biofertilizantes también son conocidos como bioinoculantes, inoculantes microbianos o inoculantes del suelo, son productos agrobiotecnológicos que contienen microorganismos vivos o latentes (bacterias u hongos, solos o combinados) y que son agregados a los cultivos agrícolas para estimular su crecimiento y productividad (Aguado, 2012). Bajo este contexto, un modelo de producción convencional de papaya necesita de un buen manejo agronómico, debido a la naturaleza de la complejidad del cultivo, de lo contrario, puede hacer que incrementen los costos de producción y disminuya la rentabilidad. Este escenario es común entre los agricultores de papaya de la localidad de La Ruana municipio de Buenavista, Michoacán, México en los últimos cinco años. Por lo anterior, es importante conocer la productividad y rentabilidad del cultivo, y estudiar otro modelo de producción agrícola alterno sustentado en biofertilizantes que revierta este escenario, apoyado en el método científico atendiendo los factores críticos que confluyen el proceso de producción agrícola in situ.

En un estudio realizado por Santamaría et al. (2015), se indicó un valor muy cercano de 10,5 ${ }^{\circ}$ Brix para el contenido de azúcares en la fruta, en la variedad de papaya Maradol Roja en Mocochá, Yucatán, México. En este mismo lugar, en otro estudio se reportó un valor de $9,8^{\circ} \mathrm{Brix}$ al día siguiente a la cosecha, con un incremento gradual hasta llegar a $10^{\circ}$ Brix en la madurez de consumo (Santamaría et al., 2009), sin embargo, los parámetros del contenido de azúcares en la fruta varían entre 8 a $11^{\circ}$ Brix (Semillas del Caribe, 2019).

Otras investigaciones referentes a características de rendimiento y calidad en sistemas convencionales de producción de papaya han mostrado valores entre 1,3 y 2,7 kg de peso del fruto, siendo el nitrógeno y el fósforo los elementos esenciales que influyen directamente en el peso de fruto (Munro et al., 2004). En el mismo sentido, Vázquez et al. (2011) en su investigación reportaron 24,4 frutos por planta en una producción bajo un sistema de fertilización mineral 235-42-222 $\mathrm{kg} \mathrm{ha}^{-1}$ y micorrizas de la especie G. mosseae, mientras que en el testigo 17,2 frutos por planta con la misma dosis de fertilización mineral; además, estos autores aseguraron que estos resultados 
fueron los beneficios encontrados que se tienen con las micorrizas y que dependen en gran parte de la especie vegetal y el hongo micorrízico empleado, en este caso la simbiosis con la parte radical de las plantas de papaya favoreció la producción, esto en Huamuxtitlán, Guerrero, México.

El objetivo de esta investigación fue comparar un modelo de producción agrícola sustentable contra el modelo de producción convencional de papaya, para identificar la producción agrícola y la relación beneficio costo.

\section{Materiales y métodos}

Para la realización de este estudio se establecieron dos huertos de papaya en la misma zona, en la localidad de La Ruana, municipio de Buenavista, Michoacán, México. El primer huerto denominado Laurel se estableció el 20 de mayo de 2015 y se implementó un modelo de producción agrícola sustentable. El segundo huerto denominado Casa Blanca se estableció el 1 diciembre de 2015 y se implementó un modelo de producción agrícola convencional.

\section{Localización y caracterización de los agroecosistemas}

El huerto Laurel se estableció a $19^{\circ} 10^{\prime} 35,99^{\prime \prime} \mathrm{N}, 102^{\circ} 42^{\prime} 31,00^{\prime \prime} \mathrm{O}$ y $335 \mathrm{~m}$ de altitud, mientras que el huerto

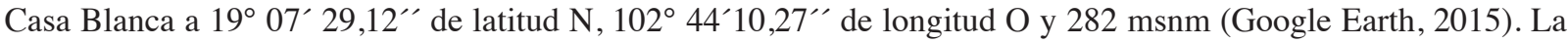
ubicación corresponde a una depresión tropical entre los ejes montañosos, que lo limitan al norte y al sur con el eje neovolcánico y la Sierra Madre del Sur del Pacífico, México (García, 1987). El tipo de suelo es vertisol pélico arcilloso (INEGI, 1983), con tipo de clima BS1 (h') W (W) que corresponde al grupo de climas secos BS1 con temperatura media anual de $27,2^{\circ} \mathrm{C}$ y $599,3 \mathrm{~mm}$ de precipitación media anual (SMN-CONAGUA, 2016).

\section{Material vegetal}

La variedad de papaya que se utilizó en dichos experimentos fue Maradol Roja comercial, la cual fue adquirida en la empresa mexicana Semilla del Caribe.

\section{Manejo del vivero}

La producción de plántula para ambos huertos se realizó en un vivero comercial localizado en Buenavista, Michoacán, México, en dos diferentes fechas durante los meses de marzo y octubre de 2015. Se utilizaron bolsas de plástico transparente de $4 \times 12 \mathrm{~cm}$, perforadas previamente para el llenado, el cual se hizo con tierra arcillosa roja con un pH de 6,5. La protección física se realizó durante un mes, con malla anti-áfidos que se instaló en la parte superior de los almácigos. Se aplicó 10 días después de la germinación fertilizante soluble en agua $2 \mathrm{~g} \mathrm{l}^{-1}$ de urea, $1 \mathrm{~g} \mathrm{l}^{-1}$ de fosfato mono amónico (MAP) y $3 \mathrm{cc} \mathrm{l}^{-1}$ de extracto de algas marinas, en intervalos de cada tres días en el riego. Los riegos se hicieron de forma manual con regadera. Se aplicaron $26 \mathrm{~g}$ de micorrizas (Glomus fasciculatum), en dosis de $10 \mathrm{~g} \mathrm{l}^{-1}$ para diluir y hacer enjuagues con aplicaciones en el riego cada tercer día, a partir de los 20 días posteriores al trasplante. Para el control de plagas se aplicó imidacloprid $2 \mathrm{cc} \mathrm{l}^{-1}$ de agua en aspersiones dirigidas al follaje cada cinco días. No se presentaron enfermedades fungosas. 


\section{Manejo agronómico de los huertos}

La preparación del suelo (desmonte, rastreo, barbecho y surcado) de los huertos se hizo con maquinaria agrícola desmonte, rastreo, barbecho y surcado. Se estableció un sistema de fertirriego presurizado a doble cintilla, con emisores a cada $20 \mathrm{~cm}$ de distancia, con un marco de plantación de 2,8 $\mathrm{m}$ entre hileras y 1,40 m entre plantas, con una densidad poblacional de 2551 plantas ha ${ }^{-1}$.

En el caso de huerto Laurel la superficie que se estableció fue de 9,10 ha con una densidad poblacional total de 23214 plantas. El intervalo de aplicación y las láminas de riego se determinaron de acuerdo con las necesidades hídricas en cada una de las etapas fenológicas del cultivo, en función del clima, cultivo y suelo; se calculó el consumo de agua del cultivo por el método práctico, con datos oficiales agro-climatológicos del distrito de riego 097 Lázaro Cárdenas de la Secretaría del Medio Ambiente y Recursos Naturales (SEMARNAT), tomando en cuenta la tasa de evapotranspiración de referencia y coeficiente de cultivo.

El diseño del modelo de producción agrícola en el huerto Laurel se estructuró para cambiar el manejo agronómico de convencional a sustentable, a través de un plan de nutrición. Previo al establecimiento del huerto se realizó un muestreo de suelo de 0 a $30 \mathrm{~cm}$ de profundidad y se llevó al laboratorio de análisis de suelos del Valle de Apatzingán para el análisis de la fertilidad inicial.

El suelo (Cuadro 1) mostró pH ligeramente alcalino (Trinidad y Rosas, 1994; Escamilla et al., 2003), muy bajo contenido de materia orgánica (Castellanos et al., 2000), y de N (Moreno, 1978; Escamilla et al., 2003), contenido

Cuadro 1. Caracterización física y química del suelo $(0-30 \mathrm{~cm}$ de profundidad $)$ del huerto Laurel y Casa Blanca, en La Ruana, municipio de Buenavista, Michoacán, México. 2016.

Table 1. Physical and chemical characterization of the soil $(0-30 \mathrm{~cm}$ deep $)$ of the Laurel and Casa Blanca gardens in La Ruana municipality de Buenavista, Michoacán, México. 2016.

\begin{tabular}{|c|c|c|c|}
\hline & & Resultado & Fuente \\
\hline Determinación & Laurel & Casa Blanca & \\
\hline $\mathrm{pH}\left(1: 2 \mathrm{H}_{2} \mathrm{O}\right)$ & 7,83 & 7,32 & Jackson (1964) \\
\hline Carbono orgánico (Walkley and Black) \% & 0,67 & 0,85 & Jackson (1964) \\
\hline $\begin{array}{l}\mathrm{N}\left(\mathrm{NO}_{3}, \mathrm{NH}_{4}\right) \text { (Arrastre de vapor con } \mathrm{MgO} \text { y Devarda } \\
\text { Alloy) } \mathrm{mg} \mathrm{kg}^{-1}\end{array}$ & 9,2 & 5,79 & Bremner (1965) \\
\hline $\mathrm{P}($ Olsen $) \mathrm{mg} \mathrm{kg}^{-1}$ & 15,8 & 16,4 & Olsen y Dean (1965) \\
\hline $\mathrm{K}\left(\mathrm{NH}_{4} \mathrm{O} \mathrm{Ac} 1 \mathrm{~N} \mathrm{pH} \mathrm{7)} \mathrm{mg} \mathrm{kg-1}\right.$ & 441 & 369 & Chapman (1965) \\
\hline $\mathrm{Ca}\left(\mathrm{NH} 4 \mathrm{O} \mathrm{Ac} 1 \mathrm{~N} \mathrm{pH} \mathrm{7)} \mathrm{mg} \mathrm{kg}^{-1}\right.$ & 6864 & 3904 & Chapman (1965) \\
\hline $\mathrm{Mg}\left(\mathrm{NH}_{4} \mathrm{O} \mathrm{Ac} 1 \mathrm{~N} \mathrm{pH} \mathrm{7}\right) \mathrm{mg} \mathrm{kg}^{-1}$ & 1240 & 861 & Chapman (1965) \\
\hline Fe (DTPA y absorción atómica) mg kg-1 & 5,51 & 18,4 & Lindsay y Norvell (1978) \\
\hline $\mathrm{Cu}$ (DTPA y absorción atómica) mg kg-1 & 1,88 & 1,22 & Lindsay y Norvell (1978) \\
\hline Zn (DTPA y absorción atómica) mg kg-1 & 1 & 0,48 & Lindsay y Norvell (1978) \\
\hline Mn (DTPA y absorción atómica) mg kg-1 & 8,52 & 12,5 & Lindsay y Norvell (1978) \\
\hline B (Fotocolorimetría de azometina- $\mathrm{H}, \mathrm{CaCl}_{2} 1 \mathrm{M}$ ) $\mathrm{mg} \mathrm{kg}^{-1}$ & 1,43 & 1,11 & Enriquez (1989) \\
\hline $\begin{array}{l}\text { C.I.C. }\left(\mathrm{NH}_{4} \mathrm{O} \text { Ac } 1 \mathrm{~N} \text { pH 7) destilación y titulación }\right. \\
\text { cmol(+) } \mathrm{kg}^{-1}\end{array}$ & 43 & 30 & Chapman (1965) \\
\hline Densidad aparente (probeta) $\mathrm{Mg} \mathrm{m}^{-3}$ & 1,25 & 1,33 & \\
\hline $\mathrm{Na}\left(\mathrm{NH}_{4} \mathrm{O} \mathrm{Ac} 1 \mathrm{~N} \mathrm{pH} \mathrm{7}\right) \mathrm{mg} \mathrm{kg}^{-1}$ & 74 & 210 & Chapman (1965) \\
\hline
\end{tabular}

Adaptado de Escamilla et al. (2003) / Adapted from Escamilla et al. (2003). 
bajo de P y Fe, contenido alto de K, Ca y Mg, contenido medio de Cu (Castellanos et al., 2000), bajo contenido de Zn (Trinidad y Rosas, 1994; Escamilla et al., 2003) y Mn (Viets y Lindsay, 1973; Escamilla et al., 2003), suficiente contenido de B (Trinidad y Rosas, 1994; Castellanos et al., 2000; Escamilla et al., 2003), alta capacidad de intercambio catiónico (Cottenie, 1980; Escamilla et al., 2003), densidad aparente con compactación media, nivel de sodio bajo (Castellanos et al., 2000).

El diseño de producción se basó en el ensayo de aplicación de fertilización al cultivo con el $70 \%$ de biofertilizantes fermentados y $30 \%$ de fertilizantes químicos. Se aplicó al suelo 7,5 1 ha $^{-1}$ de algas marinas, 1785 1 ha $^{-1}$ de súper magro mejorado (abono líquido elaborado a base de estiércol de vaca, melaza, residuos vegetales y minerales traza, mediante un proceso fermentación aeróbica por diversos microorganismos naturales), 11771 ha $^{-1}$ de súper magro reforzado (abono líquido preparado a base de suero de leche, agua y elementos menores $\mathrm{Fe}, \mathrm{Zn}$, $\mathrm{B}, \mathrm{Co}, \mathrm{Mg}, \mathrm{Mb}$ y Mn), 5801 ha $^{-1}$ de caldo ceniza (producto elaborado con agua, ceniza vegetal y jabón, mediante un proceso de cocción), $6 \mathrm{~kg} \mathrm{ha}^{-1}$ de micorriza (Glomus fasciculatum), 138,6 kg ha-1 de $\mathrm{CO}\left(\mathrm{NH}_{2}\right)_{2}, 128,1 \mathrm{~kg} \mathrm{ha}^{-1}$ de $\left(\mathrm{NH}_{4}\right) 2 \mathrm{SO}_{4}, 41 \mathrm{ha}^{-1}$ de $\mathrm{H}_{3} \mathrm{PO}_{4}, 126 \mathrm{~kg} \mathrm{ha}^{-1}$ de $\mathrm{NH}_{4} \mathrm{H}_{2} \mathrm{PO}_{4}, 41$ ha $^{-1}$ de $\mathrm{K}_{2} \mathrm{HPO}_{4}, 94,5 \mathrm{~kg}$ ha ${ }^{-1}$ de $\mathrm{K}_{2} \mathrm{SO}_{4}, 80 \mathrm{~kg}$ ha ${ }^{-1}$ de $\mathrm{KCl}, 36 \mathrm{~kg} \mathrm{ha}^{-1}$ de $\mathrm{FeSO}_{4}, 39 \mathrm{~kg} \mathrm{ha}^{-1}$ de $\mathrm{KCl}, 6 \mathrm{~kg} \mathrm{ha}^{-1}$ de $\mathrm{B}$ y $21 \mathrm{ha}^{-1}$ de $_{2} \mathrm{SO}_{4}$, durante todo el proceso de producción.

La dinámica de nutrición del cultivo se obtuvo con el análisis de la concentración mineral foliar, así se ajustaron las prácticas de fertilización y se aseguró el abasto nutricional del cultivo. Los criterios que se utilizaron para determinar la fertilización foliar fueron con base en la sintomatología observada en campo, corroborada con el resultado del análisis foliar. El fertilizante foliar que se aplicó fue 61 ha $^{-1}$ de algas marinas, 761 ha $^{-1}$ de súper magro mejorado, 341 ha $^{-1}$ de súper magro reforzado, 651 ha $^{-1}$ de caldo ceniza, 921 ha $^{-1}$ de caldo sulfocálcico (producto preparado con agua, azufre y cal, mediante un proceso de cocción), $201 \mathrm{ha}^{-1} \mathrm{de}_{2} \mathrm{HPO}_{4}, 20 \mathrm{~kg} \mathrm{ha}^{-1} \mathrm{de} \mathrm{KCl,} 2 \mathrm{~kg}$ ha $^{-1}$ de $\mathrm{FeSO}_{4}, 4 \mathrm{~kg} \mathrm{ha}^{-1}$ de $\mathrm{ZnSO}_{4} \cdot 7 \mathrm{H}_{2} \mathrm{O}, 0,25 \mathrm{~kg} \mathrm{ha}^{-1}$ de B y 41 ha $^{-1}$ de Ca.

En la sanidad del cultivo se utilizaron productos orgánicos para prevención y control de enfermedades como caldo ceniza y sulfocálcico al $2 \%$, fosetil aluminio $2 \mathrm{~g} \mathrm{l}^{-1}$, además de productos como mancozeb $3 \mathrm{~g} \mathrm{l}^{-1}$ y metalaxil + clorotalonil $2 \mathrm{~g} \mathrm{l}^{-1}$ dirigidos al follaje. Para la prevención y el control de plagas se utilizaron repelentes de insectos elaborados a partir de extracto de ajo y canela $\left(5 \mathrm{ml} \mathrm{l}^{-1}\right)$, extracto de neem $\left(5 \mathrm{ml} \mathrm{l}^{-1}\right)$, aceite de soya $\left(5 \mathrm{ml} \mathrm{l}^{-1}\right)$ y otros productos adquiridos en casas comerciales como aceite parafínico $\left(3 \mathrm{ml} \mathrm{l}^{-1}\right)$, sales potásicas $\left(3 \mathrm{ml} \mathrm{l}^{-1}\right)$, azufre humectable $\left(5 \mathrm{~g} \mathrm{l}^{-1}\right)$ y bifentrina + abamectina $\left(2 \mathrm{ml} \mathrm{l}^{-1}\right)$, bajo un criterio biorracional. El control de malezas se realizó en forma manual.

En el huerto Casa Blanca la superficie que se estableció fue de 8,12 ha con una densidad poblacional de 2551 plantas ha-1 con un total de 20717 plantas. El diseño de producción se estructuró de acuerdo con las actividades agrícolas acostumbradas por el productor y su experiencia en el cultivo, basadas en el funcionamiento del sistema de producción (testigo). De igual manera que en el huerto Laurel, se determinaron los riegos y el muestreo de suelo para el análisis de fertilidad inicial.

La caracterización física y química del suelo se presenta en el Cuadro 1, bajo los siguientes criterios de interpretación: pH ligeramente alcalino (Trinidad y Rosas, 1994; Escamilla et al., 2003), bajo contenido de materia orgánica (Castellanos et al., 2000), muy bajo contenido de N (Moreno, 1978; Escamilla et al., 2003), medio contenido de $\mathrm{P}, \mathrm{K}, \mathrm{Ca}, \mathrm{Fe}$ y Cu, muy alto contenido de $\mathrm{Mg}$, muy bajo contenido de $\mathrm{Zn}$ (Castellanos et al., 2000), bajo contenido de Mn (Viets y Lindsay, 1973; Escamilla et al., 2003), medio contenido de B (Trinidad y Rosas, 1994; Castellanos et al., 2000; Escamilla et al., 2003), alta capacidad de intercambio catiónico (Cottenie, 1980; Escamilla et al., 2003), densidad aparente con compactación media, nivel de sodio medio (Castellanos et al., 2000). Asimismo, se aplicó al suelo $198 \mathrm{~kg} \mathrm{ha}^{-1} \mathrm{de} \mathrm{CO}\left(\mathrm{NH}_{2}\right)_{2}, 73 \mathrm{~kg} \mathrm{ha}^{-1} \mathrm{de}\left(\mathrm{NH}_{4}\right)_{2} \mathrm{SO}_{4}, 96 \mathrm{~kg} \mathrm{ha}^{-1}$ de $\mathrm{NH}_{4} \mathrm{NO}_{3}, 121 \mathrm{ha}^{-1}$

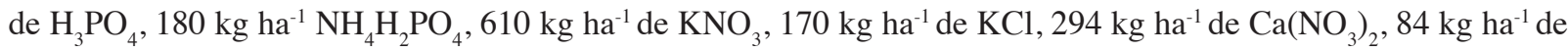
$\mathrm{Mg}\left(\mathrm{NO}_{3}\right)_{2}, 18,5 \mathrm{~kg} \mathrm{ha}^{-1}$ de $\mathrm{FeSO}_{4}, 20,4 \mathrm{~kg} \mathrm{ha}{ }^{-1}$ de $\mathrm{ZnSO}_{4} \cdot 7 \mathrm{H}_{2} \mathrm{O}, 8,7 \mathrm{~kg} \mathrm{ha}^{-1}$ de $\mathrm{CuSO}_{4}, 21 \mathrm{~kg} \mathrm{ha}{ }^{-1}$ de $\mathrm{MnSO}_{4}, 3 \mathrm{~kg}$ 
ha $^{-1}$ de B y $60 \mathrm{~kg} \mathrm{ha}^{-1}$ de azufre agrícola al 99,5\%, distribuido en las tres etapas fenológicas (vegetativa, floración y fructificación) del cultivo.

Para determinar la fertilización foliar primero se obtuvo la concentración mineral foliar. Los criterios de interpretación se sustentaron con base en la experimentación de respuesta del cultivo hacia los fertilizantes. El fertilizante foliar que se aplicó fue 81 ha $^{-1} \mathrm{de} \mathrm{K}_{2} \mathrm{HPO}_{4}, 4 \mathrm{~kg} \mathrm{ha}^{-1}$ de $\mathrm{KCl}, 21 \mathrm{ha}^{-1}$ de Fe, $41 \mathrm{ha}^{-1}$ de $\mathrm{Zn}, 41 \mathrm{ha}^{-1}$ de Ca y $1,51 \mathrm{ha}^{-1}$ de Ca, distribuido durante todo el ciclo de vida del cultivo.

Para la prevención-control de plagas se utilizó Abamectina $\left(1,5 \mathrm{cc} \mathrm{l}^{-1}\right)$ y Amitraz $\left(1,5 \mathrm{cc} \mathrm{l}^{-1}\right)$, azufre humectable $\left(5 \mathrm{~g} \mathrm{l}^{-1}\right)$ y Spirodiclofen $\left(2 \mathrm{cc} \mathrm{l}^{-1}\right)$ para control de ácaros principalmente; asimismo, se aplicaron los insecticidas Imidacloprid $\left(2 \mathrm{cc} \mathrm{l}^{-1}\right)$ agua, Metamidofos $\left(1 \mathrm{cc} \mathrm{l}^{-1}\right)$ y Omeotato $\left(1 \mathrm{cc} \mathrm{l}^{-1}\right)$ para insectos chupadores. En el control de enfermedades se aplicó de manera periódica y constante aspersiones al follaje de Mancozeb (5 $\left.\mathrm{g} \mathrm{l}^{-1}\right)$, Clorotalonil (4 $\left.\mathrm{g} \mathrm{l}^{-1}\right)$, Thiabendazol $\left(2 \mathrm{~g} \mathrm{l}^{-1}\right)$, Metalaxil $\left(4 \mathrm{~g}^{-1}\right)$. El control de malezas se realizó en forma manual y con aplicaciones de glifosato $\left(10 \mathrm{cc} \mathrm{l}^{-1}\right)$.

\section{Caracteristicas del experimento}

Se utilizaron dos unidades experimentales (huerto Laurel y huerto Casa Blanca), un tratamiento por unidad (sustentable y convencional), posteriormente se calculó el tamaño de muestra por unidad experimental y finalmente se realizó un muestreo aleatorizado simple.

\section{Muestreo probabilístico}

En ambos huertos se realizó un muestreo aleatorizado para poblaciones finitas (ecuación 1). En el huerto Laurel el tamaño de muestra fue de 306 plantas y en el huerto Casa Blanca de 305 plantas.

$$
n=\frac{N * Z_{a}^{2} * p * q}{i^{2}(N-1)+Z_{a}^{2} * p * q}
$$

(ecuación 1)

$\mathrm{N}=$ total de la población.

$\mathrm{Z}^{2}=$ valor correspondiente a la distribución de Gauss.

$\mathrm{Z}_{\mathrm{a}=0,5}=1,96^{2}$ la igualdad es de $95 \%$.

$p=(p=0,5)$.

$q=1-p($ sí $p=50 \%, q=50 \%)$.

$i=$ error que se prevé si es del $5 \%$.

\section{Variables de estudio}

Las variables de estudio que se evaluaron fueron: peso de fruto (PF) (los frutos sazones que alcanzaron la madurez organoléptica se cortaron y pesaron en kg en una balanza mecánica Ohaus ${ }^{\circledR}$ modelo 2400-11), sólidos solubles totales (SST), frutos con madurez de consumo (siete meses después de trasplante), se cortaron y se extrajo pulpa para colocarla en un refractómetro analógico ATC y tomar lectura en ${ }^{\circ}$ Brix, frutos por planta (FP) (el conteo de frutos se realizó en el tramo de fructificación de la planta (sección inferior, media y superior) a partir del primer fruto, incluyendo frutos hermafroditos elongados y frutos pentandrios, y excluyendo los deformes). 


\section{Análisis estadístico}

La prueba estadística que se utilizó fue paramétrica multivariada. Para comprobar la homocedasticidad (homogeneidad de varianzas), se empleó la prueba de Levene. Para corroborar las condiciones de parametricidad se usó la prueba de Kolmogorov-Smirnov y Lilliefors para la verificación de la normalidad de las distribuciones. Con la finalidad de demostrar el supuesto de normalidad, se realizó una prueba de Kolmogorov-Smirnov con corrección de significación Lilliefors (K-S-L) según sugieren Steinskog et al. (2007) y recomiendan Oztuna et al. (2006).

Se realizó análisis de varianza multivariado para determinar las diferencias significativas de peso de fruto, número de frutos y sólidos solubles totales, en función de las condiciones de producción, empleándose un estadístico de prueba Pillai's. Se compararon los resultados de cada una de las variables entre las condiciones de producción, mediante una prueba no paramétrica U de Mann-Whitney. La significancia estadística para todas las pruebas realizadas fue con un $\alpha=0,05$ ( $\mathrm{p}<0,05)$. El análisis de los resultados se realizó con el programa estadístico STATISTICA versión 13.3 (TIBCO Inc., 2017).

\section{Análisis económico}

Se utilizaron dos matrices de registro de campo, una con el costo total de la inversión y otra con los precios de venta sobre los pesos por corte de fruta que se cosechó y dio origen a la estructura del análisis económico. Los indicadores financieros fueron:

Costo total de inversión (CTI), fue el resultado de la suma de todos los insumos y factores internos (mano de obra de jornales, labores culturales, costo de riego), dado por el precio del insumo ( $\mathrm{Pj}$ ) multiplicado por la cantidad de insumo (Yj) (ecuación 2).

$$
C T I=\sum_{k=1}^{n} P j Y j
$$

ecuación 2

Ingreso total (IT), es el valor de la producción y fue el resultado de multiplicar el rendimiento neto (RN) a nivel de huerto por el precio de venta promedio (PVP) del productor (ecuación 3).

$$
I T=R N * P V P \quad \text { ecuación } 3
$$

El rendimiento neto $(\mathrm{RN})$ se determinó mediante rendimiento total $(\mathrm{RT})$ menos la merma (M) (ecuación 4). El RT se obtuvo a partir de la matriz de precio de venta.

$$
R N=R T-M \quad \text { ecuación } 4
$$

La utilidad neta (UN) fue el resultado de la diferencia aritmética entre IT y costo total de inversión total (CTI) (ecuación 5).

$$
U N=I T-C T I \quad \text { ecuación } 5
$$

La relación beneficio costo $(\mathrm{R} / \mathrm{BC})$ fue el resultado de la división de IT entre el costo total de la inversión (CTI) (ecuación 6). En su interpretación, se determina cuántos dólares se obtienen por cada dólar invertido en la actividad. 


$$
R B C=\frac{I T}{C T I} \quad \text { ecuación } 6
$$

La rentabilidad (R) se determinó por el método Dupont, respecto a esto, Restrepo (2015) describe que este método agrupa el margen neto de utilidades, la rotación de los activos totales y el apalancamiento financiero. El cálculo de la rentabilidad fue el resultado de multiplicar el margen neto (MN) por la rotación de activos (RA) (ecuación 7). El margen neto (MN) se obtuvo a partir de dividir la utilidad neta (UN) entre la venta neta (VN). La rotación de activos (RA) se obtuvo a partir de dividir la venta neta (VN) entre el activo total (AT).

$$
R=\left\lfloor M N=\frac{U N}{V N}\right] *\left\lfloor R A=\frac{V N}{A T}\right\rfloor
$$

ecuación 7

La venta neta (VN) fue el resultado de la diferencia aritmética del ingreso total (IT) menos las mermas de la producción en términos monetarios (M) (ecuación 8).

$$
V N=I T-M \quad \text { ecuación } 8
$$

El punto de equilibrio (PE) es la cantidad de ingresos que igualan a la totalidad de costos y gastos en que incurre normalmente una empresa (Morales y Morales, 2009) y para el cálculo se utilizó los costos fijos (CF) divididos entre IT menos los costos variables (CV) (ecuación 9).

$$
P E=\frac{C F}{I T-C V}
$$

ecuación 9

\section{Resultados}

\section{Análisis estadístico}

La prueba de Levene's $(\mathrm{p} \leq 0,05)$ mostró diferencia significativa entre las varianzas del peso de fruto y frutos por planta, por lo que no se asumió la homogeneidad de varianzas. En contraste, el contenido de sólidos solubles no mostró diferencia significativa entre las varianzas (Cuadro 2).

Cuadro 2. Análisis de Levene's $(\mathrm{p} \leq 0,05)$ para las variables peso de fruto, contenido de sólidos solubles y frutos por planta de papaya (Carica papaya L.) variedad Maradol Roja. La Ruana municipio de Buenavista, Michoacán, México. 2016.

Table 2. Levene's analysis ( $\mathrm{p} \leq 0.05)$ for the variables fruit weight, content of soluble solids, and fruits per papaya plant (Carica papaya L.) Maradol Roja variety. La Ruana municipality of Buenavista, Michoacan, Mexico. 2016.

\begin{tabular}{lccccc}
\hline Variable & CM Efecto & CM Error & F de Levene & gl & Valor p \\
\hline Peso de fruto $(\mathrm{kg})$ & 1,6861 & 0,09108 & 18,51160 & 609 & 0,000020 \\
Contenido de sólidos solubles $\left({ }^{\circ}\right.$ Brix) & 0,3208 & 0,72201 & 0,44436 & 609 & $0,505277 \mathrm{~ns}$ \\
Frutos por planta (Núm.) & 682,5304 & 73,66096 & 9,26584 & 609 & 0,002435 \\
\hline
\end{tabular}

ns: no significativo ( $\mathrm{p} \leq 0,05) / \mathrm{ns}$ : not significant $(\mathrm{p} \leq 0.05)$.

$\mathrm{CM}=$ cuadrado medio $/ \mathrm{MS}=$ mean square .

$\mathrm{gl}=$ grados libertad $/ \mathrm{df}=$ degreess of freedom. 
En la prueba de significación, la normalidad de las puntuaciones en los gráficos de las variables frutos por planta y peso de fruto (Figura 1 y 2), se presentó una ligera distribución asimétrica derecha, sin embargo, sólidos solubles totales mostró una distribución normal (los valores observados casi se emparejan con los valores normales esperados) (Figura 3).

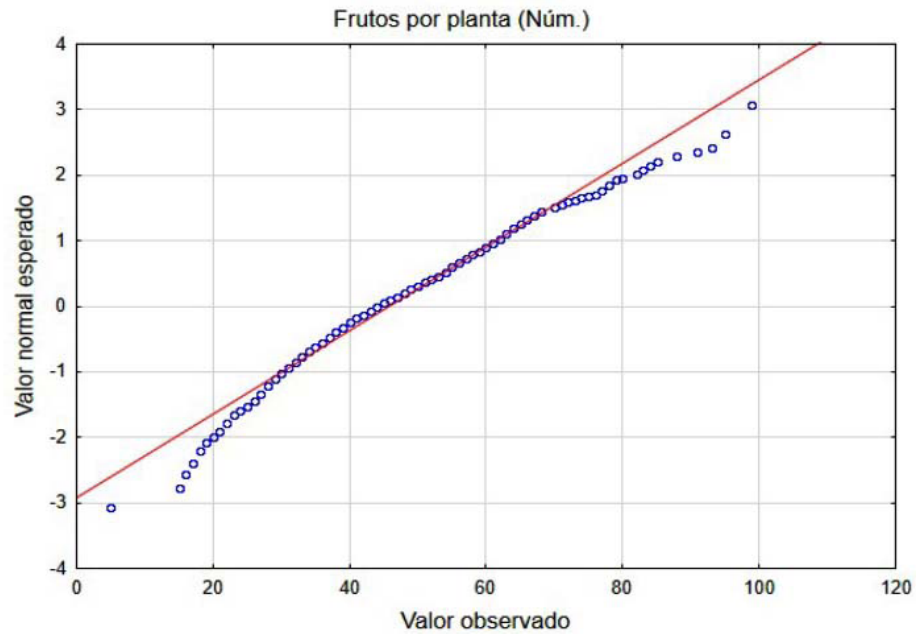

Figura 1. Gráfico de normalidad de frutos por planta de papaya (Carica papaya L.) variedad Maradol Roja, para los huertos Laurel y Casa Blanca mediante los métodos de muestreo aleatorio simple realizado a los siete meses después del trasplante. La Ruana municipio de Buenavista, Michoacán, México. 2016.

Figure 1. Fruit normality graph per papaya plant (Carica papaya L.) Maradol Roja variety, for the Laurel and Casa Blanca orchards using simple random sampling methods, performed seven months after transplantation. La Ruana municipality of Buenavista, Michoacan, Mexico. 2016.

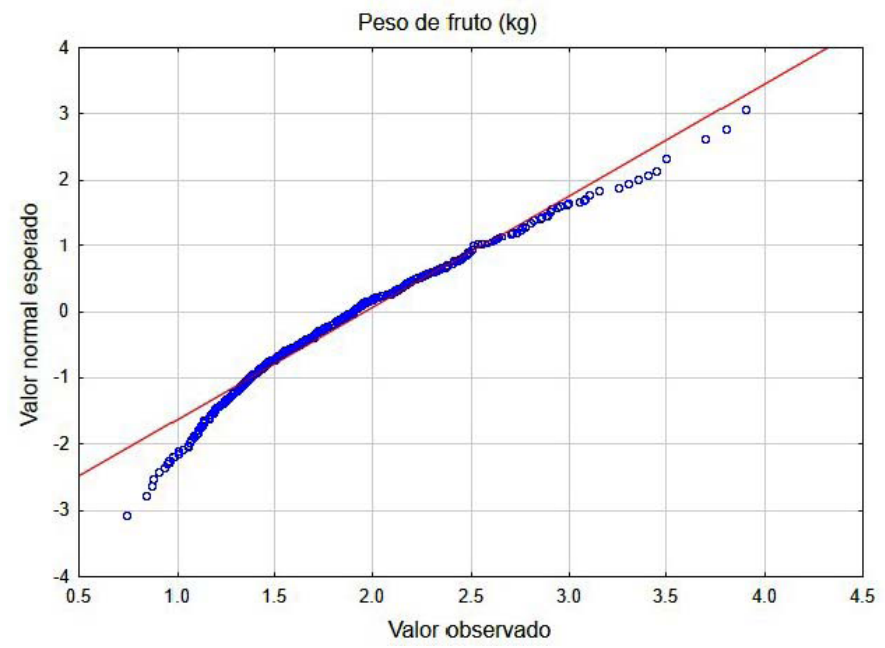

Figura 2. Gráfico de normalidad de peso de fruto de papaya (Carica papaya L.) variedad Maradol Roja, de los huertos Laurel y Casa Blanca mediante los métodos de muestreo aleatorio simple realizado a los siete meses después del trasplante. La Ruana municipio de Buenavista, Michoacán, México. 2016.

Figure 2. Normality graph of papaya fruit weight (Carica papaya L.) Maradol Roja variety, from the Laurel and Casa Blanca orchards using simple random sampling methods, performed seven months after transplantation. La Ruana municipality of Buenavista, Michoacan, Mexico. 2016. 


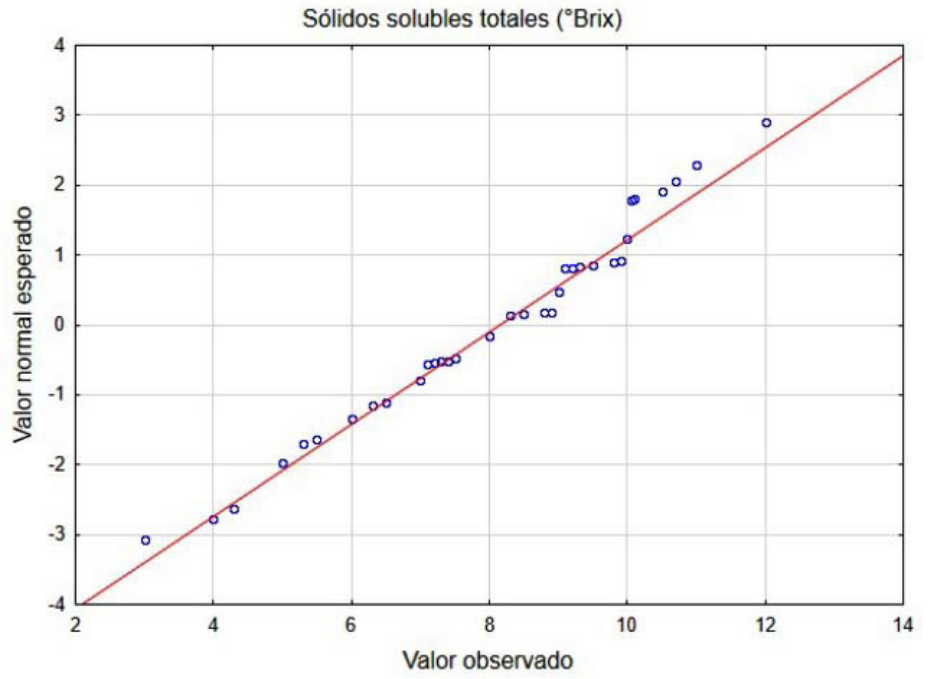

Figura 3. Gráfico de normalidad de sólidos solubles totales de papaya (Carica papaya L.) variedad Maradol Roja, de los huertos Laurel y Casa Blanca mediante los métodos de muestreo aleatorio simple realizado a los siete meses después del trasplante. La Ruana municipio de Buenavista, Michoacán, México. 2016.

Figure 3. Normatily grpah of total soluble solids of papaya (Carica papaya L.), Maradol Roja variety, from the Laurel and Casa Blanca orchards using simple random sampling methods performed seven months after transplantation. La Ruana municipality of Buenavista, Michoacan, Mexico. 2016.

En el caso de frutos por planta en el huerto Casa Blanca el valor de p fue superior a 0,05 pero muy cercano a dicho valor, por lo que se decidió rechazar la hipótesis nula (no existió ninguna diferencia en la productividad y la rentabilidad del cultivo de papaya con la implementación de un modelo de producción agrícola sustentable de papaya en comparación con un modelo convencional), dado la considerable variabilidad que se mostró en los resultados (Cuadros 3 y 4 ).

Cuadro 3. Análisis de Kolmogorov-Smirnov $(\mathrm{p} \leq 0,05)$ para las variables peso de fruto, sólidos solubles y total de frutos de papaya (Carica papaya L.) variedad Maradol Roja, de los huertos Laurel y Casa Blanca en La Ruana municipio de Buenavista, Michoacán, México. 2016.

Table 3. Kolmogorov-Smirnov analysis $(\mathrm{p} \leq 0.05)$ for the variables fruit weight, soluble solids, and total papaya fruit (Carica papaya L.) Maradol Roja variety, from the Laurel and Casa Blanca orchards in La Ruana municipality of Buenavista, Michoacan, Mexico. 2016.

\begin{tabular}{llccc}
\hline \multirow{2}{*}{ Condición } & & \multicolumn{3}{c}{ Kolmogorov-Smirnov $^{\mathbf{a}}$} \\
\cline { 3 - 5 } & & Estadístico Z & gl & Significancia \\
\hline Peso de fruto $(\mathrm{kg})$ & Laurel & 0,076 & 306 & 0 \\
\multirow{2}{*}{ Sólidos solubles totales $\left({ }^{\circ}\right.$ Brix) } & Casa Blanca & 0,068 & 305 & 0,002 \\
& Laurel & 0,207 & 306 & 0 \\
Frutos por planta (Núm) & Casa Blanca & 0,134 & 305 & 0 \\
& Laurel & 0,096 & 306 & 0 \\
& Casa Blanca & 0,051 & 305 & 0,054 \\
\hline
\end{tabular}

${ }^{a}$ Corrección de la significación de Lilliefors / a Lilliefors Significance Correction. $\mathrm{gl}=$ grados libertad $/ \mathrm{df}=$ degree free. 
Cuadro 4. Promedios de peso de fruto $(\mathrm{kg})$, sólidos solubles ( ${ }^{\circ}$ Brix), frutos por planta (Núm) de papaya (Carica papaya L.), variedad Maradol Roja, para los huertos Laurel y Casa Blanca, mediante los métodos de muestreo aleatorio simple realizado a los siete meses después del trasplante. La Ruana municipio de Buenavista, Michoacán, México. 2016.

Table 4. Fruit weight averages (kg), soluble solids ( ${ }^{\circ}$ Brix), fruits per plant (No.) of papaya (Carica papaya L.) Maradol Roja variety, for Laurel and Casa Blanca orchards using random sampling methods simple performed seven months after transplant. La Ruana municipality of Buenavista Michoacan, Mexico. 2016.

\begin{tabular}{lccc}
\hline \multicolumn{1}{c}{ Tratamiento } & Peso de fruto $(\mathbf{k g})$ & Sólidos solubles totales $\left({ }^{\circ}\right.$ Brix) & Frutos por planta $($ Núm) \\
\hline Laurel *MPAS & $1,7162 \pm 0,45$ & $8,5145 \pm 1,43$ & $38,0653 \pm 11,92$ \\
Casa Blanca *MPAC & $2,2059 \pm 0,58$ & $7,7813 \pm 1,46$ & $53,7091 \pm 14,60$ \\
\hline
\end{tabular}

*MPAS: modelo de producción agrícola sustentable, *MPAC: modelo de producción agrícola convencional / *MPAS: sustainable agricultural production model, *MPAC: conventional agricultural production model.

El análisis de varianza $(\mathrm{p} \leq 0,05)$ mostró que los dos modelos de producción agrícola difirieron de forma significativa en cada una de variables.

En la prueba U de Mann-Whitney ( $\mathrm{p} \leq 0,05)$, para muestras independientes, $y$ donde se asume que $(\mathrm{p} \leq 0,05)$ es bilateral y los valores críticos de Z son $\pm 1,96$ el valor de $\mathrm{Z}$ ajustada (significación asintótica bilateral) fue mayor para las tres variables evaluadas (Cuadro 5), y existió diferencia significativa entre los dos huertos.

Cuadro 5. Prueba U de Mann-Whitney $(\mathrm{p} \leq 0,05)$ para las variables peso de fruto, sólidos solubles totales y frutos por planta de papaya (Carica papaya L.), variedad Maradol Roja, en los huertos Laurel y Casa Blanca en La Ruana municipio de Buenavista, Michoacán, México. 2016.

Table 5. Mann-Whitney U test $(\mathrm{p} \leq 0.05)$ for the variables fruit weight, total soluble solids, and fruits per papaya plant (Carica papaya L.), Maradol Roja variety, in the Laurel and Casa Blanca orchards in La Ruana Municipality of Buenavista, Michoacan, Mexico. 2016.

\begin{tabular}{|c|c|c|c|c|c|}
\hline \multirow[b]{2}{*}{ Variable } & \multicolumn{2}{|c|}{ Suma de Rangos } & \multirow[t]{2}{*}{ U de Mann-Whitney } & \multirow[t]{2}{*}{$\mathrm{Z}$ ajustada } & \multirow[t]{2}{*}{$\mathbf{p}$} \\
\hline & Laurel & Casa Blanca & & & \\
\hline Peso fruto $(\mathrm{kg})$ & 70949,0 & 116017 & 23978 & $-10,3989$ & 0,000000 \\
\hline Sólidos solubles totales $\left({ }^{\circ}\right.$ Brix $)$ & 107957,5 & 79008,5 & 32343,5 & 6,6614 & 0,000000 \\
\hline Frutos por planta (Núm) & 64708,5 & 122257,5 & 17737,5 & $-13,2621$ & 0,000000 \\
\hline
\end{tabular}

Tamaño de la muestra Laurel 306, Casa Blanca 305 / sample size Laurel 306, Casa Blanca 305.

Los valores medios obtenidos para peso de fruto en los huertos fueron: 1,71 kg para Laurel y 2,20 kg para Casa Blanca (Cuadro 4), con diferencia significativa $(\mathrm{p} \leq 0,05)$ entre sí.

Para sólidos solubles totales se encontró diferencia significativa ( $\mathrm{p} \leq 0,05)$, el valor medio para el huerto Laurel fue $8,5^{\circ}$ Brix y para el huerto Casa Blanca $7,8^{\circ}$ Brix (Cuadro 4). El modelo sustentable fue significativamente superior al modelo convencional.

En frutos por planta se encontró diferencia significativa $(p \leq 0,05)$. En el huerto Casa Blanca el valor de la media muestral fue de 53,72, en el caso del huerto Laurel el valor medio encontrado fue de 38,06 (Cuadro 4). 


\section{Análisis económico}

En el huerto Laurel el costo total de la inversión fue menor, debido principalmente al ahorro económico en la fertilización y los insumos agrícolas. El costo de los jornales permaneció igual, esto se debió a la realización de las mismas actividades agrícolas del cultivo (Cuadro 6).

Cuadro 6. Costo total de la inversión del cultivo de papaya (Carica papaya L.) variedad Maradol Roja por concepto de inversión de los huertos Laurel y Casa Blanca. La Ruana municipio de Buenavista, Michoacán, México. 2016.

Table 6. Total investment cost of papaya cultivation (Carica papaya L.) Maradol Roja variety for investment concept of the Laurel and Casa Blanca orchards. La Ruana municipality of Buenavista, Michoacan, Mexico. 2016.

\begin{tabular}{|c|c|c|}
\hline Concepto de inversión & Laurel & Casa Blanca \\
\hline Riego por cintilla y preparación de terreno (USD $\$$ ha $^{-1}$ ) & 812,62 & 717,02 \\
\hline Fertilización (USD \$ ha ${ }^{-1}$ & 620,62 & 1180,76 \\
\hline Insumos agrícolas (USD $\$ \mathrm{ha}^{-1}$ ) & 1108,56 & 1169,22 \\
\hline Jornales (USD $\$$ ha $^{-1}$ ) & 6195,03 & 6195,03 \\
\hline Costo total de inversión (USD \$ ha-1) & 8736,83 & 9262,03 \\
\hline
\end{tabular}

En el huerto Laurel se obtuvo un rendimiento total de 77,88 $\mathrm{t} \mathrm{ha}^{-1}$, una merma de 6,02 $\mathrm{t} \mathrm{ha}^{-1} \mathrm{y}$ un rendimiento neto de $67,86 \mathrm{t} \mathrm{ha}^{-1}$. En el huerto Casa Blanca el rendimiento total fue de 56,38 t ha-1 ${ }^{-1}$, con una merma de $12,36 \mathrm{t}$ ha $^{-1} \mathrm{y}$ un rendimiento neto de $42,02 \mathrm{t} \mathrm{ha}^{-1}$.

El ingreso total resultó favorable para el huerto Laurel (USD \$ 19638,74 ha $^{-1}$ ), se recuperó el costo total de la inversión (USD \$ 8736,83 ha-1), generó una utilidad neta favorable de USD \$ 10901,91 ha $^{-1}$, haciendo atractiva la bondad del modelo de producción agrícola sustentable, lo cual quedó evidenciado con la relación beneficio costo de 2,24. En el huerto Casa Blanca, aunque se recuperó el costo total de la inversión (USD \$ 9262,03 ha-1), no se generó la utilidad neta favorable esperada (USD $\$ 758,78 \mathrm{ha}^{-1}$ ), debido al rendimiento de la fruta y al ingreso total obtenido (USD \$ $10020,81 \mathrm{ha}^{-1}$ ), por consiguiente, la relación beneficio costo fue de 1,08.

El indicador de rentabilidad para el modelo de producción agrícola sustentable (MPAS) fue favorable y reflejó una utilidad neta de $120 \%$, lo que evidenció que por cada dólar invertido se generó 1,20 dólares. La proporción de beneficio fue generada por la rentabilidad de sus ventas sobre el rendimiento obtenido y el precio alcanzado de mercado, además de la eficiencia con que se utilizaron los activos en la elaboración de biofertilizantes y algunos repelentes de insectos para el proceso de producción.

La rentabilidad para el modelo de producción agrícola convencional (MPAC) mostró una utilidad neta de 8,19 $\%$, es decir, por cada dólar invertido se generó 0,0819 dólares. Este análisis mostró una rentabilidad del proceso de producción muy baja para el tipo de cultivo y la inversión total. El retorno del activo total (USD \$10 020,81 ha-1) reflejó el beneficio generado al productor con relación al empleo de sus activos, que en este caso se adquirieron con la compra de fertilizantes sintéticos e insumos agrícolas en las casas comerciales locales. Si se considera que el beneficio económico del productor agrícola es la diferencia entre el ingreso total y el total de la inversión, la administración de la estructura de costos de producción (indicó mayores gastos) y su esfuerzo (indicó menor ingreso) mantuvieron una distancia corta entre los ingresos y los costos de producción, de tal manera que esto se reflejó en la utilidad neta. 
El punto de equilibrio mostró para que el productor del huerto Laurel no pierda ni gane, tiene que recuperar el 38,47 \% del ingreso total o desplazar 25,82 $\mathrm{t} \mathrm{ha}^{-1}$, sin embargo, para que el productor del huerto Casa Blanca pueda llegar a este punto debe recuperar el 90,11 \% del ingreso total o desplazar 37,86 t ha ${ }^{-1}$, lo que significó, que el productor estaba teniendo pérdidas la mayoría del tiempo que duró establecido el huerto. En el primer caso (MPAS) el productor alcanzó más pronto el punto de equilibrio y recuperó más rápido la inversión total, esto se debió también al costo de producción más bajo (USD $\$ 0,13 \mathrm{~kg}^{-1}$ ) y al precio de venta más alto (USD $\$ 0,28 \mathrm{~kg}^{-1}$ ), comparado con el huerto Casa Blanca, con costo de producción de USD \$0,22 $\mathrm{kg}^{-1} \mathrm{y}$ precio de venta de USD \$ $0,24 \mathrm{~kg}^{-1}$.

\section{Discusión}

El valor medio de peso de fruto para el MPAC fue de 2,2 $\mathrm{kg}$ y para el MPAS de 1,71 kg, dichos valores mostraron estar relacionados principalmente con la nutrición de cultivo y el manejo agronómico; por lo que dicha diferencia se puede atribuir principalmente a la fertilización mineral nitrogenada y potásica diferenciada entre los huertos. Al respecto Santamaría et al. (2015), en su investigación reportaron un valor medio de 2,04 kg en peso de fruto para este cultivar Maradol con un manejo agronómico que consistió en proporcionar el tratamiento de fertilizante 200-100-200 kg ha ${ }^{-1}$ de N-P-K. Tanto los valores reportados como los obtenidos en esta investigación estuvieron dentro del rango reportado (2,2 a 2,5 kg) por la empresa productora de semillas en México (Semillas del Caribe, 2009) a excepción del valor obtenido para el huerto Laurel. En el mismo sentido, Mirafuentes y Santamaría (2014) cosecharon frutos de 1,3 a 2,0 kg para esta misma variedad, además encontraron que la mayor ventaja comercial se obtuvo cuando el cultivo se estableció en otoño invierno, debido a que no se produjeron deformaciones en el fruto (Carpeloidía) por las altas temperaturas; estos frutos carpeloides no tienen ningún valor en el mercado.

El valor medio para sólidos solubles en el MPAS fue de 8,5 ${ }^{\circ}$ Brix y para el MPAC de 7,8 ${ }^{\circ} \mathrm{Brix}$; la concentración de sólidos solubles es una característica genética que está relacionada con el genotipo de papaya Maradol utilizado (Alcántara et al., 2019); sin embargo, la principal razón de las diferencias encontradas se puede atribuir a las diferencias en las características físico químicas existentes entre suelos.

El tamaño de fruto influyó en la cantidad de azúcares en la fruta; lo anterior puede ser comparado con los resultados de otro estudio realizado en Cuba, donde reportaron 10,4 ${ }^{\circ}$ Brix para la variedad Maradol Roja, lo cual se atribuyó al tamaño y peso sobre la cantidad de masa de los frutos, teniendo en cuenta la correlación que existe entre esos caracteres (Rodríguez et al., 2014). Sin embargo, es muy difícil producir cultivares de frutos grandes con contenidos de azúcar tan altos como los cultivares de frutos pequeños (Mora y Bogantes, 2004; Rodríguez et al., 2014).

En frutos por planta los valores medios obtenidos fueron 38,06 y 52,72 para el MPAS y MPAC, en su respectivo orden. La diferencia entre frutos por planta $(14,66)$ puede ser atribuible a la fertilización utilizada en cada modelo, y a la disimilitud física y química que existe en el suelo, aún siendo el mismo agroecosistema. Estos valores, difieren con los de Alcántara et al. (2010), donde obtuvieron para la variedad Maradol Roja once frutos por planta en Tuxpan, Guerrero México, en un agroecosistema similar, pero con escasez de agua durante los meses más cálidos del año; mientras que Mirafuentes y Santamaría (2014) encontraron 22 y 27 frutos por planta en Huimanguillo, Tabasco y Mocochá, Yucatán México bajo condiciones de cielo abierto, valores aún por debajo de lo obtenido en este estudio. Resultados que sí son comparables con los obtenidos, son los encontrados por Alcántara et al. (2019), quienes encontraron para esta misma variedad Maradol un valor de 38 frutos por planta, mediante la fertilización química de urea $(46 \% \mathrm{~N})+184600+\mathrm{KCl}(66 \%)$, con la dosis 60+230+100 g planta-1 y aplicaciones de fertilizante foliar; en cambio con fertilización orgánica reportó 22 frutos por planta, utilizando fertilizante orgánico en dosis de $1,5 \mathrm{~kg}_{\text {planta }}{ }^{-1} \mathrm{y}$ también aplicaciones de fertilizante foliar, e indicaron que la fertilización química incrementó el número de frutos en la planta de papaya. 
En cuanto al rendimiento, el MPAS mostró un valor de 67,86 t ha ${ }^{-1}$, y el MPAC de 42,02 t ha ${ }^{-1}$, estos valores se pueden comparar con los reportados por Alcántara et al. (2019), quienes encontraron un rendimiento de 91,14 t ha ${ }^{-1}$ con fertilización química, y 41,77 t ha ${ }^{-1}$ con fertilización orgánica; además, demostraron que la fertilización química influyó directamente sobre el rendimiento del cultivo. Igualmente, Munro et al. (2004) reportaron para el Valle de Apatzingán, Michoacán, México, misma zona donde se realizó este experimento, un rendimiento de 80 t ha ${ }^{-1}$; asimismo, Bueno-Jáquez et al. (2005) en su investigación obtuvieron valores que van de 36,06 hasta 73,18 t ha $^{-1}$ con diferentes dosis de fertilización mineral de N P K, esto en San Juan Veracruz, México. Además, se indica un rendimiento de $57 \mathrm{t} \mathrm{ha}^{-1}$ en Huimanguillo, Tabasco y $72 \mathrm{t} \mathrm{ha-1}$ en Mocochá, Yucatán, México para esta misma variedad (Mirafuentes y Santamaría, 2014). Esto contrasta con un estudio realizado por Vázquez et al. (2011), quienes encontraron un rendimiento total de $144,9 \mathrm{t} \mathrm{ha}^{-1}$ con un ingreso total de USD \$28 504,7 ha $\mathrm{h}^{-1}$.

La diferencia de $25 \mathrm{t} \mathrm{ha}^{-1}$ en rendimiento entre sistemas estudiado, se debió en el caso del MPAC a la obtención de algunos frutos empedernidos durante toda la cosecha, por consiguiente, se desecharon en el mismo huerto, también se sumaron los frutos de la merma por presencia de hongos y bacterias, según lo reportado por los compradores. En el caso del MPAS no se presentó este problema de frutos empedernidos, solamente el problema reportado sobre la merma por los compradores. Es importante señalar que únicamente se comercializaron los frutos que reunieron los requisitos de los compradores de ambos huertos, esto se tradujo en un mayor rendimiento e ingreso neto para el MPAS. Respecto a la merma reportada, la principal razón se debió a que no se implementaron buenas prácticas agrícolas durante la cosecha, ante esto, los compradores reportaron fruta en mal estado al llegar a su destino de mercado. Aunque en un inicio no se presentaron enfermedades fungosas ni bacterianas.

El rendimiento de plantas de papaya depende del genotipo, así lo afirmaron Barrantes-Santamaría et al. (2019), al obtener en su investigación de papaya híbrido Pococí (pulpa anaranjada similar a Maradol Roja) 91,08 $\mathrm{t} \mathrm{ha}^{-1}$ con 37,7 frutos por planta, mediante la práctica de sexado convencional en el manejo agronómico del cultivo; esto en Costa Rica. Aunado a esto, Basso et al. (2008) aseguraron que observaron una tendencia al aumento del rendimiento del cultivo a medida que incrementaron las dosis del fertilizante nitrogenado. Lo anterior coincide con la práctica cultural de sexado que se realizó dentro del manejo agronómico del cultivo en ambos huertos, además de la fertilización nitrogenada utilizada.

El costo total de la inversión obtenido para cada uno de los huertos en estudio (Laurel USD \$ 8736,83 ha-1 y Casa Blanca USD \$ 9262,03 ha-1), fue menor comparado con el alcanzado por Vázquez et al. (2011) de USD \$ 10 $531,0 \mathrm{ha}^{-1}$, para esta misma variedad. Asimismo, Bueno-Jáquez et al. (2005) reportaron un costo de fertilización de USD \$ 1053,96 ha-1 el cual es mayor para el huerto Laurel y menor para el huerto Casa Blanca, estos costos reflejaron una mayor cantidad de fertilizante aplicado al cultivo en comparación con los huertos evaluados.

El ingreso neto para el huerto Laurel (USD \$ 10901,91 ha $^{-1}$ ) y Casa Blanca $\left(\$ 758,78\right.$ ha $^{-1}$ ) difirió al compararse con los resultados obtenidos por Bueno-Jáquez et al. (2005), en su investigación de papaya para este mismo indicador (USD \$ 5394,50) fue relativamente bajo en comparación del primer huerto con más del $50 \%$, mientras que para el segundo huerto es mayor que el $100 \%$. De la comparación anterior, se puede deducir que los ingresos obtenidos por concepto de venta de productos primarios pueden ser muy variables, y pueden diferir de una cosecha a otra. En este caso, las condiciones de mercado fijaron el precio del producto (papaya Maradol Roja) de acuerdo con la oferta y la demanda en el momento que se realizó la operación. Por otro lado, también influyeron factores técnicos durante el manejo agronómico del cultivo [eficacia y eficiencia de producción], los factores ambientales (bióticos y abióticos) y las condiciones de mercado (competitividad).

Por último, es relevante mencionar las ventajas y/o beneficios que se obtuvieron con la implementación del MPAS no nada más fueron en términos monetarios, sino se tradujeron en un mejoramiento de la calidad del agroecosistema, viabilidad económica del cultivo, aprovechamiento eficiente de los recursos naturales locales y una mejora en la calidad de vida del agricultor. 


\section{Conclusiones}

De acuerdo con el modelo de producción agrícola sustentable el contenido de sólidos solubles totales fue una característica favorable de la calidad del fruto, que le permitió incrementar las ventas y la preferencia de los compradores. Además, se caracterizó por tener un costo total de la inversión bajo y una rentabilidad económica de cultivo favorable, esto hizo que el modelo fuera muy atractivo económicamente y se pueda implementar entre los productores agrícolas de la región. Por otro lado, este modelo se destacó por el aprovechamiento eficiente de los recursos naturales locales del entorno y el mejoramiento en la calidad de vida de los productores, estas características con el paso del tiempo pueden llegar a cambiar la forma de pensar para producir entre los productores de la región.

El modelo de producción agrícola convencional se caracterizó por obtener un mayor peso de fruto y más frutos por planta, pero desfavorable económicamente con costos de producción altos que deben mejorarse hasta llegar a ser rentable. El cultivo evidenció ser muy exigente en cuanto a cantidades de fertilizante mineral aplicado, y también se corroboró el uso intensivo de pesticidas para poder controlar el ambiente de producción. Situación que provocó que el modelo pueda ser un desafío latente para la conservación y mejoramiento del agroecosistema.

Es recomendable antes de implementar un cultivo, reflexionar sobre las características técnicas, económicas y ambientales que muestra el modelo de producción agrícola que se implementará, para poder valorar realmente cuál es el modelo óptimo que se adapta a cada agroecosistema de producción.

\section{Agradecimientos}

Los autores agradecen al Sr. Luis Torres Chávez productor agrícola por su aportación de los huertos Laurel y Casa Blanca, además de todo el apoyo otorgado para la realización de esta investigación.

\section{Literatura citada}

Aguado, G.A. 2012. Uso de microorganismos como biofertilizantes. En: G.A. Aguado, editor, Introducción al uso y manejo de biofertilizantes en la agricultura. Instituto Nacional de Investigaciones Forestales, Agrícolas y Pecuarias, MEX. p. 35-78. ResearchGate, Berlín, DEU. https://www.researchgate.net/publication/311424135_Introduccion_al_Uso_y_Manejo_de_ los_Biofertilizantes_en_la_Agricultura (consultado 16 nov. 2018).

Alcántara, J.A., E. Hernández, S. Ayvar, A.D. Nava, y T. Brito. 2010. Características fenotípicas y agronómicas de seis genotipos de papaya (Carica papaya L.) de Tuxpan, Guerrero, México. Rev. Venez. Cienc. Tecnol. Aliment. 1:35-46.

Alcántara, J.A., C. Aguilar, S. Leyva, y A.O. Alcántara. 2019. Rendimiento y rentabilidad de genotipos de papaya en función de la fertilización química, orgánica y biológica. Rev. Mex. Cienc. Agríc. 3:575-584.

Arango, L.V., y C.A. Roman. 2000. Aspectos agroeconómicos. En: L.V. Arango, et al., editores, El cultivo de la papaya en los Llanos Orientales de Colombia. Corporación Colombiana de Investigación Agropecuaria, COL. p. 8-12. Agronet, COL. http:// bibliotecadigital.agronet.gov.co/bitstream/11348/4894/2/Cultivo\%20de\%20la\%20papaya.pdf (consultado 28 oct. 2018).

Armenta, A.D., C. García, J. Camacho, M. Apodaca, L. Gerardo, y E. Nava. 2010. Biofertilizantes en el desarrollo agrícola de México. Ra Ximhai 6:1-56.

Barrantes-Santamaría, W., C. Loria-Quirós, y L. Gómez-Alpízar. 2019. Evaluación de dos sistemas de sexado en plantas de papaya (Carica papaya) híbrido Pococí. Agron. Mesoam. 30:437-446. doi:10.15517/am.v30i1.34916

Basso, C., R. Villafañe, S. Torres, y J. Díaz. 2008. Evaluación de la uniformidad del riego y efecto del fertirriego nitrogenado en un huerto de lechosa (Carica papaya L.). Bioagro 20:105-110. 
Bremner, J.M. 1965. Total nitrogen. In: C.A. Black, editor, Methods of soil analysis. Part 2. Agronomy 9. American Society of Agronomy, Madison, WI, USA. p. 1149-1178.

Bueno-Jáquez, J.E., A. Alonso-López, V. Volke-Haller, F. Gallardo-López, M.M. Ojeda-Ramírez, y R. Mosqueda-Vázquez. 2005. Respuesta del papayo a la fertilización con nitrógeno, fósforo y potasio en un luvisol. Terra Latinoam. 23:409-415.

Castellanos, J.Z., J.X. Uvalle, y A. Aguilar. 2000. Manual de interpretación de análisis de suelos y aguas. 2da ed. Intagri, Celaya, Guanajuato, MEX.

Chapman, H.D. 1965. Cation exchange capacity. In: C.A. Black, editor, Methods of soil analysis. Part 2. Agronomy 9. American Society of Agronomy, Madison, WI, USA. p. 891-901.

Cottenie, A. 1980. Los análisis de suelos y plantas como base para formular recomendaciones sobre fertilizantes. Boletín 38 de suelos. FAO, Roma, ITA.

Enriquez, S.A. 1989. Análisis de boro en suelos y plantas mediante el método de azometina-H. Terra 7:13-20.

Escamilla, J.L., C. Saucedo, M.T. Martínez, A. Martínez, P. Sánchez, y R.M. Soto. 2003. Fertilización orgánica, mineral y foliar sobre el desarrollo y la producción de papaya cv. Maradol. Terra Latinoam. 21:157-166.

FAOSTAT. 2018. Cultivos. FAO, Roma, ITA. http://www.fao.org/faostat/es/\#data/QC (consultado 8 nov. 2018).

Flores, C.C., y S.J. Sarandón. 2002. ¿Racionalidad económica versus sustentabilidad ecológica? El ejemplo del costo oculto de la pérdida de fertilidad del suelo durante el proceso de Agriculturización en la Región Pampeana Argentina. Rev. Fac. Agron. 1:52-67.

Franquesa, M. 2016. Agricultura convencional. Agroptima Blog, FRA. https://www.agroptima.com/es/blog/agriculturaconvencional/ (consultado 3 dic. 2019).

García, E. 1987. Modificaciones al sistema de clasificación climática de Köppen. $4^{\text {ta }}$ ed. Universidad Nacional Autónoma de México, MEX.

Gliessman, S.R. 1998. Agroecología procesos ecológicos en la agricultura sostenible. CATIE, Turrialba, CRI.

Google Earth. 2015. Buenavista, Tomatlán, Michoacán México, "Escala indeterminada”. Google Maps, USA. https://www. google.com/maps/place/Buenavista+Tomat1\%C3\%A1n,+Mich.,+M\%C3\%A9xico/@ 19.2133061,-102.5964549,5425m/ data $=! 3 \mathrm{~m} 2$ ! 1e3!4b1!4m5!3m4!1 s0x 842e25f2a466358f:0xeab916b4acd8cf4b!8m2!3d19.2080937!4d-102.5870398 (consultado 23 sep. 2015).

Guzmán-Ramón, E., R. Gómez, H.A.J. Pohlan, J.C. Alvarez-Rivero, J. Pat-Fernández, and V. Geissen. 2008. Comparisons of production costs and profit of three different technology levels of papaya production in Tabasco, México. J. Agric. Rural Dev. Trop. Subtrop. 109:1-14.

INEGI (Instituto Nacional de Estadística y Geografía). 1983. Carta edafológica E. 13-3. Escala 1: 250,000. Instituto Nacional de Geografía Estadística e Informática, Colima, MEX.

Jackson, M.L. 1964. Análisis químico de suelos. Omega, Barcelona, ESP.

Lindsay, W.L., and W.A. Norvell. 1978. Development of a DTPA soil test for zinc, iron, manganese, and copper. Soil Sci. Soc. Am. J. 42:421-428.

López, M., B. Rodríguez, y M. España. 2010. Tecnologías generadas por el INIA para contribuir al manejo integral de la fertilidad del suelo. Agron.Trop. 60:315-331.

Martin, R., Á. Nexticapan, R. Herrera, S. Vergara, y A. Larqué. 2012. Efecto positivo de aplicaciones de ácido salicílico en la productividad de papaya (Carica papaya). Rev. Mex. Cienc. Agríc. 8:1637-1643. 
Michelena, R.O. 2011. Degradación de tierras en Argentina. Prevención y control. Universidad Nacional de la Plata, ARG. http://sedici.unlp.edu.ar/handle/10915/27822 (consultado 17 abr. 2020).

Mirafuentes, F., y A. Azpeitia. 2008. 'Azteca’, primer híbrido de papaya para el trópico de México. Rev. Fitotec. Mex. 31:291293.

Mirafuentes, F., y F. Santamaría. 2014. MSXJ, híbrido de papaya sin carpeloidía para el sureste de México. Rev. Mex. Cienc. Agríc. 5:1297-1301.

Mora, E., y A. Bogantes. 2004. Evaluación de híbridos de papaya (Carica papaya L.) en Pococí, Limón, Costa Rica. Agron. Mesoam. 15:39-44. doi:10.15517/AM.V15I1.11927

Morales, A., y J.A. Morales. 2009. Proyectos de inversión formulación y evaluación. McGraw Hill, MEX.

Moreno, D.R. 1978. Clasificación de pH del suelo, contenido de sales y nutrimentos asimilables. Instituto Nacional de Investigaciones Forestales, Agrícolas y Pecuarias, México D.F., MEX.

Moreno, B., y G.A. Aguado. 2012. Manejo y calidad de los biofertilizantes. En: G.A. Aguado, editor, Introducción al uso y manejo de biofertilizantes en la agricultura. Instituto Nacional de Investigaciones Forestales, Agrícolas y Pecuarias, MEX. p. 115-150. ResearchGate, Berlín, DEU. https://www.researchgate.net/publication/311424135_Introduccion_al_Uso_y_ Manejo_de_los_Biofertilizantes_en_la_Agricultura (consultado 17 nov. 2018).

Munro, D., E. Vargas, y H.R. Rico. 2004. Guía de aplicación de tecnología en papaya "Michoacán 2004 ". Guía técnica 7. Instituto Nacional de Investigaciones Forestales, Agrícolas y Pecuarias, MEX. DOCPLAYER, ESP. https://docplayer. es/37870788-Guia-de-aplicacion-de-tecnologia-en-papaya-michoacan-2004.html (consultado 19 feb. 2019).

Olsen, S.R., and L.A. Dean. 1965. Phosphorus. In: C.A. Black, editor, Methods of soil analysis. Part 2. Agronomy 9. American Society of Agronomy, Madison, WI, USA. p. 1035-1049.

Oztuna, D., A.H. Elhan, and E. Tuccar. 2006. Investigation of four different normality tests in terms of type I. Error rate and power under different distributions. Turk. J. Med. Sci. 36(3):171-176.

Pengue, W. 2001. Impacto de la expansión de la soja en la Argentina. Globalización, desarrollo agropecuario e ingeniería genética: Un modelo para armar. Biodiversidad 29:7-14.

Posada, L., R. Gómez, J. Pérez, M. Reyes, and O. Norman. 2010. Development of a new papaya (Carica papaya L.) hybrid IBP 42-99. Interciencia 35:461-465.

Restrepo, J.A. 2015. Una aproximación estocástica al impacto de los inventarios en las empresas comercializadoras de Izúcar de Matamoros mediante el análisis del indicador Dupont y el punto de equilibrio. Vincula Tégica 1(1):198-226.

Rivas, P., G. Mora, D. Téliz, y A. Mora. 2003. Influencia de variedades y densidades de plantación de papayo (Carica papaya L.) sobre las epidemias de mancha anular. Rev. Fitotec. Mex. 21:109-116.

Rodríguez, J., Y. Díaz, A. Pérez, Z. Natali, y P. Rodríguez. 2014. Evaluación de la calidad y el rendimiento en papaya silvestre (Carica papaya L.) de Cuba. Cul. Trop. 35(3):36-44.

SADER-SIAP (Secretaría de Desarrollo Rural - Servicio de Información Agroalimentaria y Pesquera). 2019. Anuario estadístico de la producción agrícola. SIAP, MEX. https://nube.siap.gob.mx/cierreagricola/ (consultado 3 abr. 2019).

Santamaría, F., R. Díaz, E. Sauri, F. Espadas, J.M. Santamaría, y A. Larqué. 2009. Características de calidad de frutos de papaya maradol en la madurez de consumo. Agric. Téc. Méx. 35:347-353.

Santamaría, F., F. Mirafuentes, M.J. Zavala, y E. Vázquez. 2015. calidad de frutos de materiales comerciales de papaya roja producidos en Yucatán, México. Agron. Costarricense 39:161-167. 
Semillas del Caribe. 2019. Productos. Maradol Roja. Semillas del Caribe, MEX. https://www.semillasdelcaribe.com.mx/ producto/maradol-roja-2/ (consultado 16 abr. 2020).

Serrato, N., C. Castillo, I. Díaz, M. Patiño, y L. Cabrera. 2017. La ingeniería al servicio de la sustentabilidad: una tendencia para el crecimiento del sector agrícola. Rev. Tecnol. 16(2):127-136.

SMN-CONAGUA (Servicio Meteorológico Nacional - Comisión Nacional del Agua). 2016. Datos meteorológicos. SMN, MEX. http://smn.cna.gob.mx/es/ (consultado 25 ene. 2017).

Steinskog, D.J., D.B. Tjøstheim, and N.G. Kvamstø. 2007. A Cautionary note on the use of the Kolmogorov-Smirnov test for normality. Monthly Weather Rev. 135:1151-1157.

Storck, V., D.G. Karpouzas, and F. Martín-Laurent. 2017. Towards a better pesticide policy for the European Union. Sci. Total Environ. 575:1027-1033. doi:10.1016/j.scitotenv.2016.09.167

TIBCO Inc. 2017. STATISTICA data analysis software system. Version 13.3 for Windows. TIBCO Inc, Tulsa, OK, USA. https:// www.tibco.com/products/data-science (accessed Apr. 20, 2019).

Trinidad, A., y D. Rosas. 1994. Clasificación generalizada de algunas determinaciones químicas de suelo y tejido vegetal, útiles para la interpretación de resultados en fertilidad de suelos. Colegio de Postgraduados, Montecillo, MEX.

Vargas-González, G., V.P. Álvarez-Reyna, C. Guigón-López, P. Cano-Ríos, y M. García-Carrillo. 2019. Impacto ambiental por el uso de plaguicidas en tres áreas de la producción de la Comarca Lagunera, México. Ciencia UAT 13(2):113-127. doi:10.29059/cienciauat.v13i2.1141

Vázquez, M.V., M.L. Arévalo, D. Jean, y J.L. Escamilla. 2011. Evaluación del efecto de micorrizas en la producción y calidad de papaya maradol (Carica papaya L.). Agroproductividad 4:27-32.

Viets, F.G., and W.L. Lindsay. 1973. Testing soil for zinc, cupper, manganese and iron. In: M.L. Walsh, and D.B. James, editors, Soil testing and plant anal. Soil Science Society of America, Madison, WI, USA. p. 151-172. 